\title{
Effect of a novel orally bioavailable CXCR4 inhibitor, AMD070, on the metastasis of oral cancer cells
}

\author{
DAISUKE UCHIDA $^{1}$, NOBUYUKI KURIBAYASHI ${ }^{1}$, MAKOTO KINOUCHI $^{1}$, \\ YUTA SAWATANI ${ }^{1}$, MICHIKO SHIMURA ${ }^{1}$, TOSHIMITSU MORI ${ }^{1}$, \\ TOMONORI HASEGAWA $^{1}$, YOUJI MIYAMOTO ${ }^{2}$ and HITOSHI KAWAMATA ${ }^{1}$ \\ ${ }^{1}$ Department of Oral and Maxillofacial Surgery, Dokkyo Medical University School of Medicine, Tochigi 321-0293;
${ }^{2}$ Department of Oral Surgery, Tokushima University Graduate School of Biomedical Sciences, Tokushima 770-8504, Japan
}

Received November 9, 2017; Accepted April 3, 2018

DOI: $10.3892 /$ or.2018.6400

\begin{abstract}
We have previously demonstrated that the stromal cell-derived factor (SDF-1)/CXCR4 system is involved in the metastasis of head and neck cancer. Additionally, it has been revealed that the blockade of CXCR4 by subcutaneous daily injection with AMD3100, a CXCR4 antagonist, may be effective in preventing metastasis in CXCR4-related head and neck cancer. Recent investigations have suggested that AMD070, a novel orally bioavailable inhibitor of CXCR4, may be minimally invasive compared with AMD3100. In the present study, we examined the effect of AMD070 on metastasis induced by the SDF-1/CXCR4 axis in B88-SDF-1 oral cancer cells, which express high levels of SDF-1 and CXCR4. Although treatment with AMD070 did not affect the anchorage-dependent growth of B88-SDF-1 cells, it significantly suppressed the anchorage-independent growth. Moreover, the SDF-1/CXCR4-dependent migration and invasion of B88-SDF-1 cells was significantly inhibited following treatment with AMD070. Subsequently, we performed an experimental therapy using AMD070 to prevent the distant metastasis of B88-SDF-1 cells in vivo. Daily oral administration of AMD070 significantly inhibited the lung metastasis of B88-SDF-1 cells in nude mice. These results indicated that AMD070 could be useful as a novel orally bioavailable inhibitor of oral cancer metastasis.
\end{abstract}

\section{Introduction}

We previously demonstrated that oral cancer cells expressing the chemokine receptor CXCR4 specifically metastasize to

Correspondence to: Professor Daisuke Uchida, Department of Oral and Maxillofacial Surgery, Dokkyo Medical University School of Medicine, 880 Kita-Kobayashi, Mibu, Shimo-tsuga, Tochigi 321-0293, Japan

E-mail: udai@dokkyomed.ac.jp

Key words: oral cancer, CXCR4, metastases, AMD070, oral administration cervical lymph nodes via a gradient of stromal cell-derived factor-1 (SDF-1; also known as CXCL12) produced by the lymphatic stroma (1-4). Moreover, oral cancer cells that acquired an SDF-1/CXCR4 autocrine loop exhibited enhanced cell motility and contributed to lung metastasis (5). Recent investigations have indicated that CXCR4 expression is involved in the metastatic potential of salivary gland cancer (6). Furthermore, we have demonstrated that blocking CXCR4 with 1,1'-[1,4-phenylenebis(methylene)] bis-1,4,8,11-tetraazacyclotetradecane octahydrochloride (AMD3100; also known as plerixafor), a CXCR4 antagonist, may have the potency to prevent metastasis in CXCR4-related head and neck cancer (5-7). AMD3100 was first identified as a bicyclam derivative with potent activity against HIV infection (8). However, AMD3100 is now clinically available for the mobilization of hematopoietic stem cells into the blood stream (9). Although it is well known that the SDF-1/CXCR4 system contributes to both lymph node and distant metastasis in several types of cancer (10-15), many investigators have observed that AMD3100 also inhibits the invasion and metastasis of CXCR4-expressing cancer cells, both in vitro and in vivo (16-19). However, for the prevention of cancer metastasis, patients must receive a daily injection of AMD3100, as it has an estimated distribution half-life of $0.3 \mathrm{~h}$ and a terminal half-life of $5.3 \mathrm{~h}$ (9); therefore, this treatment places a burden on patients.

AMD070 (also called AMD11070) is a selective and orally bioavailable antagonist of CXCR4 with a half-life of 7.6-12.6 h (20,21). The mechanism by which AMD070 antagonizes CXCR4 has been determined to involve the formation of a hydrogen bond between the benzimidazole of AMD070 and the Tyr45 residue of CXCR4 (20,21). No apparent acute toxicity has been reported in oral bioavailability studies using AMD070 (20). Despite the potential of AMD070 to contribute to cancer therapy, only two studies in acute lymphoblastic leukemia and pancreatic cancer have been performed to determine the efficacy of AMD070 as a cancer treatment in mice $(22,23)$, and only one study has been performed using the oral administration route despite the high oral bioavailability of this drug (23). Thus, in the present study, we examined the effect of AMD070 on the SDF-1/CXCR4 axis of oral cancer cells in vitro, and performed experimental 
chemotherapy via oral administration using a mouse model of SDF-1/CXCR4-dependent metastasis.

\section{Materials and methods}

Ethics statement. All of the in vivo experiments were performed in Tokushima University. The mice were handled in accordance with the recommendations in the Guide for the Care and Use of Laboratory Animals of the National Institutes of Health. The protocol was approved by the Animal Research Committee, Tokushima University (permit no. 11111). Briefly, all mice were housed under pathogen-free conditions, received food and water ad libitum, and were maintained in a 12-h light/dark cycle in an appropriate temperature-controlled room. All surgery and euthanasia were performed under sodium pentobarbital anesthesia, and all efforts were made to minimize suffering. B88 cells (1) were originally established from a patient with tongue cancer in 1988. The Ethics Committee of the Tokushima University Hospital waived the need for consent on the use of this cell line (permit no. 453).

Cells and cell culture. Oral cancer cells were deemed free of mycoplasma and bacterial contaminants. B88 cells highly metastasize to cervical lymph nodes, when the cells are inoculated in the masseter muscle of nude mice, but rarely metastasize to lungs by intravenous inoculation $(1,5)$. B88-SDF-1 cells were the transfectants that acquired distant metastatic potential in vivo through the introduction of the SDF-1 expression vector (5). The cells were maintained in Dulbecco's modified Eagle's medium (DMEM; Sigma-Aldrich: Merck KGaA, Darmstadt, Germany) supplemented with $10 \%$ fetal calf serum (FCS), $100 \mu \mathrm{g} / \mathrm{ml}$ streptomycin, and $100 \mathrm{U} / \mathrm{ml}$ penicillin in a humidified atmosphere of $95 \%$ air and $5 \% \mathrm{CO}_{2}$ at $37^{\circ} \mathrm{C}$.

Mice and the in vivo study. BALB/c nude mice were purchased from CLEA Japan, Inc. (Osaka, Japan). The mice were maintained under pathogen-free conditions. The experiments were initiated when the mice were 8 weeks of age and were performed as previously described $(1,5)$. Briefly, the cells were inoculated into the blood vessels of nude mice $\left(1 \times 10^{6}\right)$. These mice were sacrificed at day 49. The presence or absence of distant metastases was confirmed by hematoxylin and eosin (H\&E) staining. For experimental chemotherapy, the mice were treated by the daily oral administration of $0.2 \mathrm{ml}$ of saline for a vehicle or the same volume of AMD070 (2 mg/kg; AdooQ BioScience LLC, Irvine, CA, USA) according to the intraperitoneal administration in vivo described by Morimoto et al (23).

MTT assay. Cells were seeded on a 96-well plate (Falcon; BD Biosciences, Franklin Lakes, NJ, USA) at $5 \times 10^{3}$ cells/well in DMEM containing $10 \%$ FCS. Twenty-four hours later, the cells were treated with or without $2 \mu \mathrm{M}$ AMD3100 (Sigma-Aldrich: Merck KGaA) or $6.6 \mu \mathrm{M}$ AMD070. After 24 or $48 \mathrm{~h}$, the number of cells was quantified by an assay using 3-(4,5-dimethylthiazol-2-yl)-2,5-diphenyltetrazolium bromide (MTT; Sigma-Aldrich: Merck KGaA).

Soft agar assay. B88 cells were seeded at a density of $1 \times 10^{5}$ cells/well in 6 -well plates in $2 \mathrm{ml}$ of $0.6 \%$ agar (Wako
Pure Chemical Industries, Ltd., Osaka, Japan) supplemented with DMEM in the presence of $10 \%$ FCS. Twenty-four hours later, the cells were treated with or without $6.6 \mu \mathrm{M}$ AMD070. After 14 and 21 days, the colonies containing $>20$ cells were counted.

Wound healing assay. After $24 \mathrm{~h}$ of culture, a linear wound was generated by scraping some confluent monolayers of cells with a $200-\mu 1$ pipet tip in the presence of either $2 \mu \mathrm{M}$ AMD3100 or $6.6 \mu \mathrm{M}$ AMD070. Unattached cells were washed off with agitation. Cells were imaged by a digital camera (DP21; Olympus Corp., Tokyo, Japan) at the same grid location after $48 \mathrm{~h}$. Each line was plated and wounded in triplicate.

In vitro cell migration and invasion assays. The in vitro migration and invasion of B88 cells were evaluated using Transwells (Corning, Inc., Corning, NY, USA) and a BioCoat ${ }^{\mathrm{TM}}$ Matrigel $^{\mathrm{TM}}$ Invasion Chamber with BD Matrigel Matrix (Falcon; BD Biosciences), respectively, as previously described (18). Briefly, $5 \times 10^{4}$ cells were seeded on polycarbonate filters of $8 \mu \mathrm{m}$ pore size in a Transwell migration assay, and $5 \times 10^{5}$ cells were seeded on Matrigel-coated polycarbonate filters of $8 \mu \mathrm{m}$ pore size in a Matrigel invasion assay both in DMEM containing $10 \%$ FCS in the upper and lower chambers. After $48 \mathrm{~h}$ of culture, the cells and Matrigel on the upper-surface of the membrane were wiped out with a cotton swab in both assays, and the membrane was removed from the chamber, and stained with $\mathrm{H} \& \mathrm{E}$ at room temperature. After enclosure of the membrane into cover glass, plugged cells in pores and cells that attached to the underside of the membrane were counted in 10 fields at a high-power view (magnification, x400) with a BX53 upright microscope (Olympus Corp.) by a third person blinded to treatment conditions. In some experiments, $2 \mu \mathrm{M}$ AMD3100 or $6.6 \mu \mathrm{M}$ AMD070 were co-incubated with cells seeded in the upper chamber. All of the assays were performed in triplicate.

Statistical analysis. Statistical differences between the means among groups were evaluated with StatView 4.5 (Abacus Concepts, Berkeley, CA, USA) using one-way analysis of variance (ANOVA), with the level of significance at $\mathrm{P}<0.05$. The significance level was set at $5 \%$ for each analysis.

\section{Results}

Effect of AMD070 on cell growth. We previously demonstrated that AMD3100, a CXCR4 inhibitor, did not affect the anchorage-dependent growth of B88-mock or B88-SDF-1 cells, but did inhibit the anchorage-independent growth of the B88-SDF-1 cells (5). We compared the effect of AMD070 with AMD3100 on the growth of B88-SDF-1 cells. Neither inhibitor affected the anchorage-dependent growth of the B88-mock or B88-SDF-1 cells (Fig. 1). Additionally, AMD070 did not induce any cytotoxicity in the CAL-27 oral cancer cells lacking CXCR4 expression, which were treated at the same concentration (data not shown). Conversely, AMD070 significantly suppressed the anchorage-dependent growth of the B88-SDF-1 cells (Fig. 2A and B).

Effect of AMD070 on SDF-1/CXCR4-dependent cell migration and invasion. We next investigated the effect of AMD070 


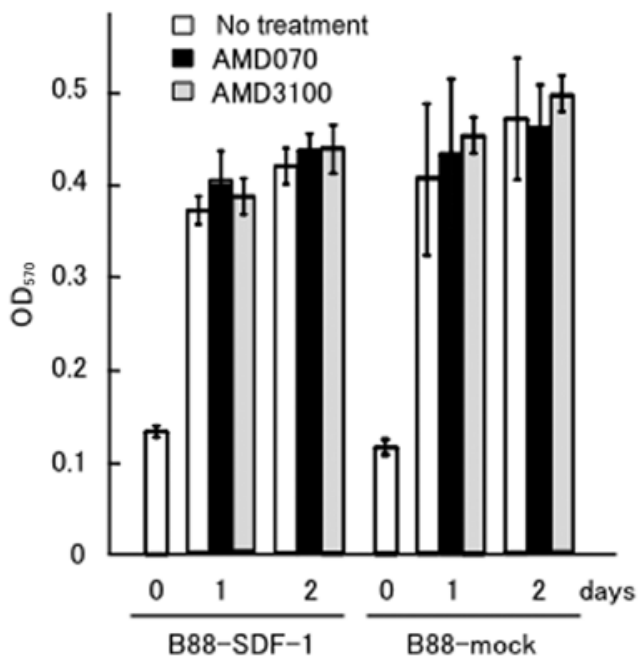

Figure 1. Effect of CXCR4 inhibitors on the anchorage-dependent growth of cells. B88-mock or B88-SDF-1 cells were treated with either $6.6 \mu \mathrm{M}$ AMD070 (black) or $2 \mu \mathrm{M}$ AMD3100 (grey). Neither inhibitor affected the anchorage-dependent growth of the B88-mock or B88-SDF-1 cells. The effect of CXCR4 inhibitors on cell growth was evaluated using an MTT assay. The error bars indicate the standard deviation. SDF-1, stromal cell-derived factor-1.

on the SDF-1/CXCR4-dependent migration and invasion of cells. Wound healing assays revealed that the enhanced motility of B88-SDF-1 cells was significantly impaired by treatment with AMD3100 and AMD070 (Fig. 3A and B). AMD070 also significantly inhibited the migration and Matrigel invasion of B88-SDF-1 cells, as demonstrated by the Transwell chamber assays, similar to the effect of treatment with AMD3100 (Fig. 3C and D).

Effect of AMD070 on the lung metastasis of B88-SDF-1 cells. Next, we performed intravenous inoculation of B88-SDF-1 cells with acquired metastatic potential to the lungs (5). Metastatic nodules in the lungs were histopathologically detected in $5 / 9$ of the control mice, but were only detected in 2/10 of the mice treated with AMD070 (Fig. 4A). Moreover, a significant reduction in the number of metastatic lung nodules was observed in the mice treated with AMD070 when compared with the control (16 vs. 3), during a 7-week observation period. We also confirmed the presence of metastatic cancer cells in extracted lung tissues using a quantitative Alu-PCR assay. Consequently, the expression of human Alu DNA in mice treated with AMD070 was significantly lower than in mice treated with saline (Fig. 4B). Furthermore, during the 49-day observation, AMD070 treatment did not induce body weight loss despite the tumor bearing-condition of the mice (control, $11.1 \pm 17.5 \%$ loss; AMD070, $0.9 \pm 14.5 \%$ loss), indicating that there is less toxicity associated with the daily oral administration of AMD070 (data not shown). In addition, we did not detect the apparent macroscopic organ abnormalities associated with the daily oral administration of AMD070.

\section{Discussion}

In the present study, we investigated the effect of a novel orally bioavailable CXCR4 inhibitor, AMD070, on the metastasis of oral cancer cell lines in vitro and in vivo. The findings obtained
A

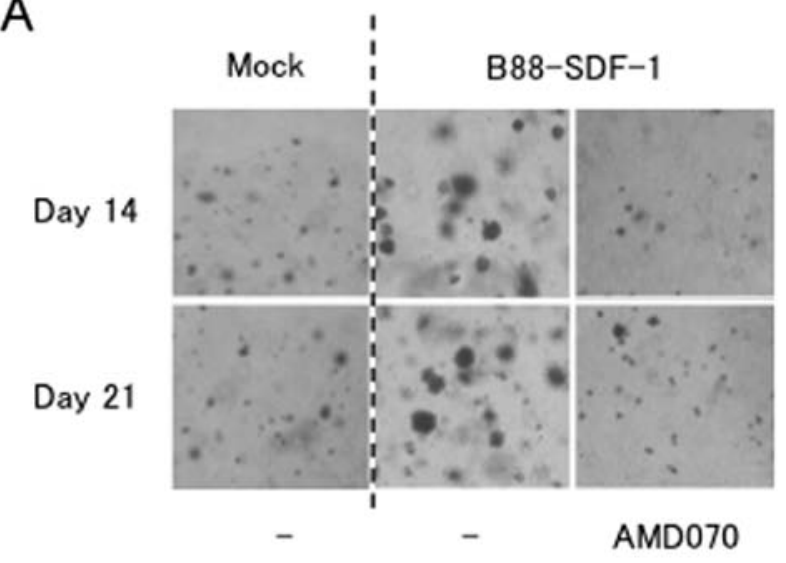

B

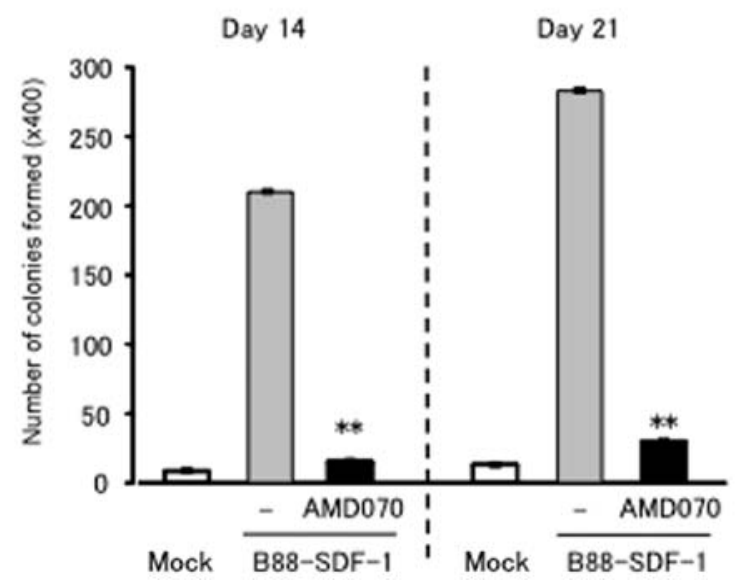

Figure 2. Effect of AMD070 on the anchorage-independent growth of cells. (A) AMD070 inhibited the acquired anchorage-independent growth of B88-SDF-1 cells in soft agar. Top and bottom: cell colony formation at days 14 and 21, respectively. Magnification, x400. (B) The number of colonies in mock-transfectants (white columns) and B88-SDF-1 cells treated with (black) or without (grey) AMD070. AMD070 significantly suppressed the anchorage-dependent growth of B88-SDF-1 cells. Bars represent the standard deviation of triplicate samples. ${ }^{* * *} \mathrm{P}<0.01$, compared with the non-treated B88-SDF-1 cells, as determined by one-way ANOVA. SDF-1, stromal cell-derived factor-1; ANOVA, analysis of variance.

from the present series of experiments are as follows. Firstly, AMD070 did not affect anchorage-dependent cell growth, but significantly suppressed anchorage-independent growth of B88-SDF-1 cells. Secondly, AMD070 significantly inhibited the migration and Matrigel invasion of the cells. Thirdly, oral administration of AMD070 significantly inhibited lung metastasis of the cells in nude mice. These results indicated that AMD070 may represent a novel orally bioavailable inhibitor for the metastases of oral cancer.

The chemokine receptor CXCR4 and its cognate ligand SDF-1 have been implicated in B-cell lymphopoiesis, bone marrow myelopoiesis, vascular development, cardiogenesis and HIV infection (24-27). More recently, the SDF-1/CXCR4 system has been demonstrated to determine the destination of various tumor cells, including breast, ovarian, prostate and kidney cancer, brain tumor, lung and thyroid cancer, neuroblastoma and malignant melanoma cells (10-15,28-30). Due to its classification as a cell surface $G$ protein-coupled receptor, CXCR4 has been investigated for its potential as a therapeutic target for these diseases, particularly for the treatment of 
A

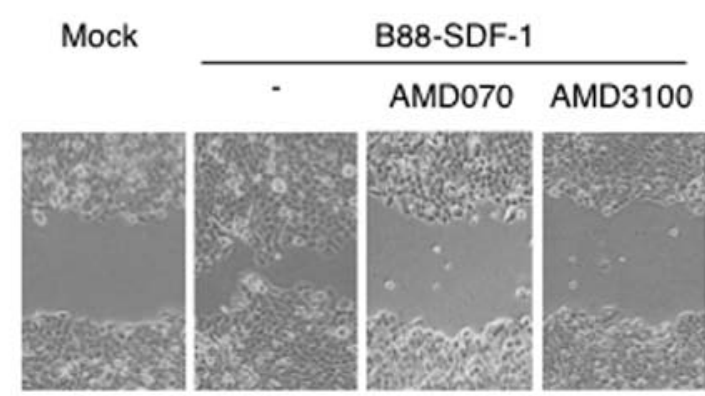

B

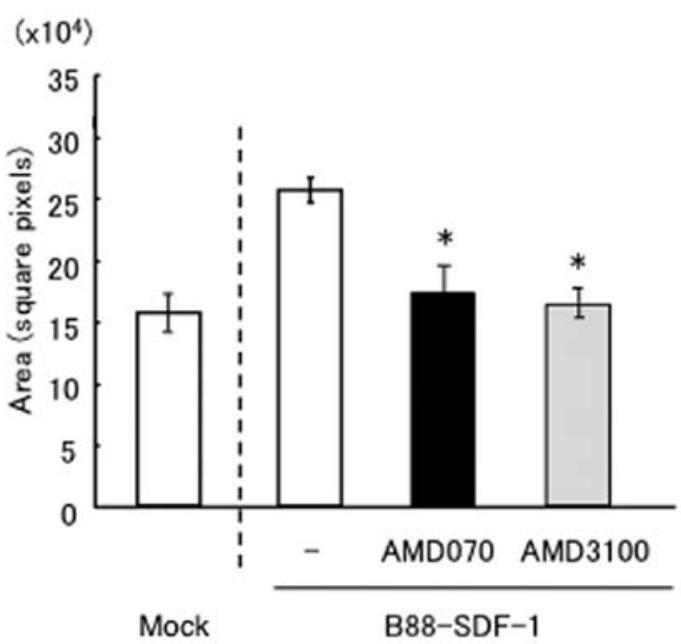

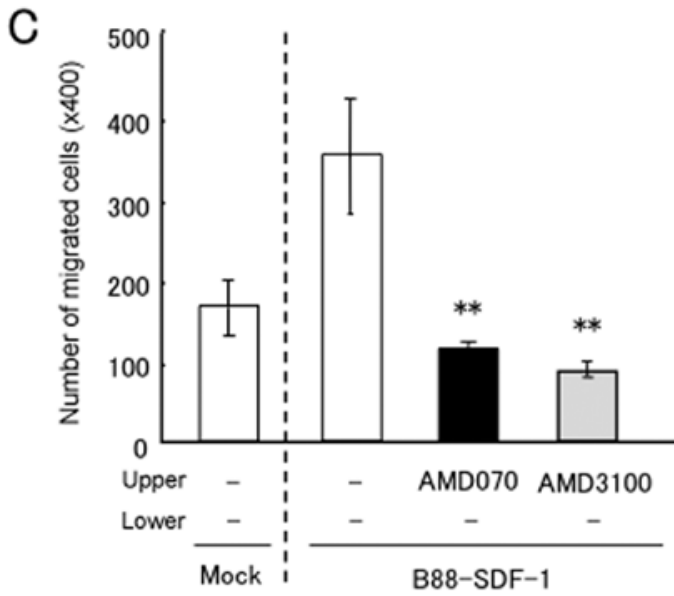

D

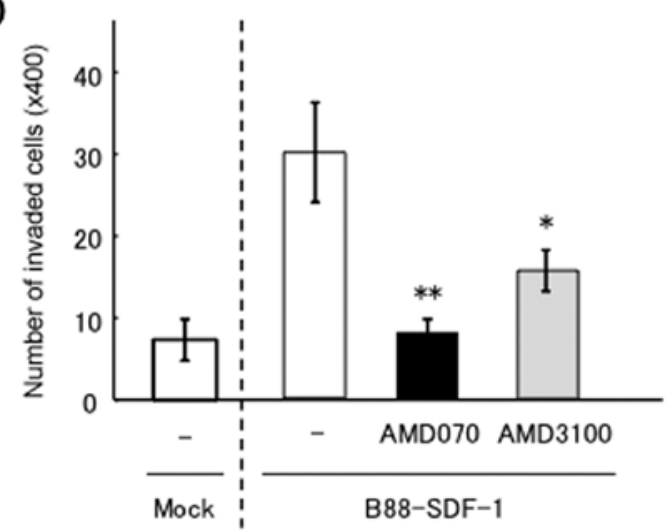

Figure 3. Effect of AMD070 on the migration and invasion of cells. (A) A wound-healing assay was performed in the presence of either AMD070 (black) or AMD3100 (grey). (B) Quantitative data derived from (A). "P<0.05, compared with the untreated control, as determined by one-way ANOVA. (C) The motility of B88-SDF-1 cells in the presence of either AMD070 (black) or AMD3100 (grey) in the upper chamber was examined using a Transwell migration assay. ${ }^{* *} \mathrm{P}<0.05$, compared with the untreated control, as determined by one-way ANOVA. Both CXCR4 inhibitors significantly suppressed the migration of B88-SDF-1 cells. (D) The invasion of B88-SDF-1 cells in the presence of either AMD070 (black) or AMD3100 (grey) in the upper chamber was examined using a Matrigel invasion assay. Both CXCR4 inhibitors significantly suppressed the invasion of B88-SDF-1 cells. ${ }^{* *} \mathrm{P}<0.01$ or ${ }^{*} \mathrm{P}<0.05$, compared with the untreated control, as determined by one-way ANOVA. Bars represent the standard deviation of triplicate samples. ANOVA, analysis of variance; SDF-1, stromal cell-derived factor-1.

A

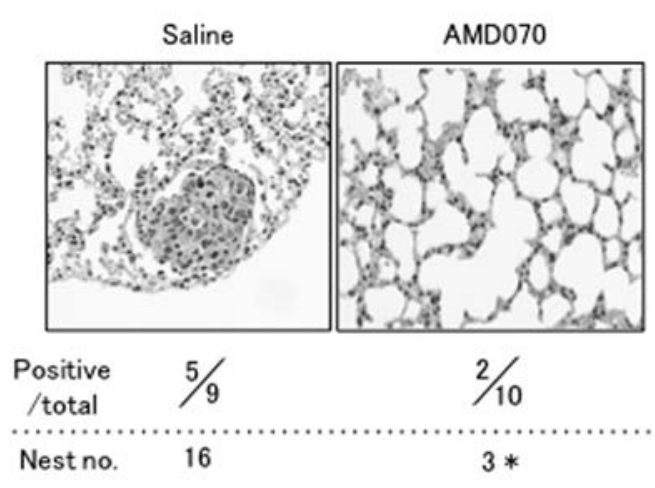

B

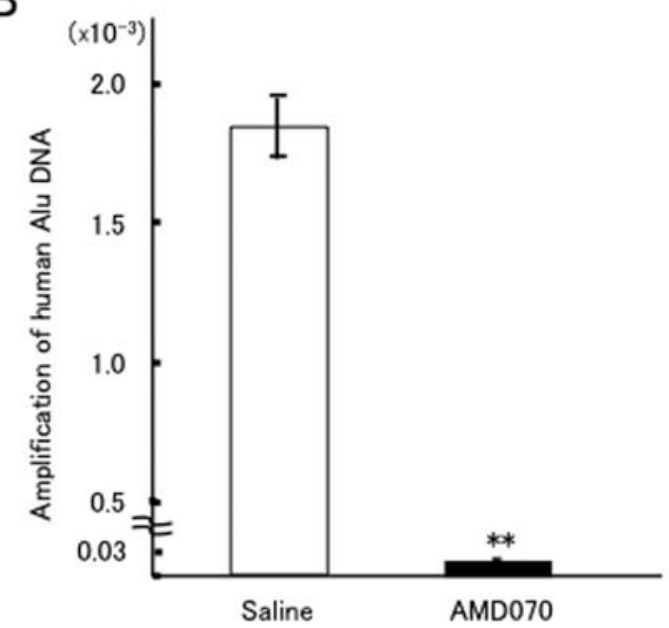

Figure 4. Effect of AMD070 on the metastasis of B88-SDF-1 cells to the lung. B88-SDF-1 cells were intravenously inoculated into nude mice. The mice were then treated with a daily oral administration of $0.2 \mathrm{ml}$ saline or an equal volume of AMD070 (2 mg/kg). (A) Representative H\&E staining of the lungs from saline-treated (left) or AMD070-treated (right) nude mice. The number of nude mice positive for lung metastasis and the number of tumor nests are shown in the middle and lower columns, respectively. A significant reduction in the number of metastatic lung nodules was observed in the mice treated with AMD070. "P $<0.05$, compared with the saline control, as determined by one-way ANOVA. (B) Quantitative analysis by Alu-PCR was performed on the extirpated lung tissues. Expression of human Alu DNA in the mice treated with AMD070 was significantly lower than in the mice treated with saline. ${ }^{* *} \mathrm{P}<0.01$, compared with the saline control, as determined by one-way ANOVA. SDF-1, stromal cell-derived factor-1; H\&E, hematoxylin and eosin; ANOVA, analysis of variance. 
HIV (27). While several new compounds that act against CXCR4 are under preclinical development (31), the only currently clinically available inhibitor of CXCR4 is AMD3100 (plerixafor or Mozobil), which is used for hematopoietic stem cell mobilization in patients with non-Hodgkin's lymphoma and multiple myeloma (9). Although we, and numerous other investigators, have demonstrated the efficacy of CXCR4 inhibition in the prevention of cancer metastasis $(5-7,18,31)$, the pharmacokinetics of AMD3100 deem it unsuitable for use via oral administration due to the large size and cationic nature of the compound (32).

AMD070 was initially developed as an orally bioavailable antagonist of CXCR4, capable of suppressing the replication of X4 (T-tropic) HIV-1 and the interaction of gp120/CXCR4 $(20,21)$. AMD070 has been characterized as an allosteric inhibitor, which involves the formation of a hydrogen bond between the benzimidazole of AMD070 and the Tyr45 residue of CXCR4; the $\mathrm{IC}_{50}$ value of AMD070 was also determined to be $13 \mathrm{nM}$ (33). In the present study, we used AMD070 at a concentration of $6.6 \mu \mathrm{M}$, according to the results of a previous study (34), and no cytotoxicity was recorded in the oral cancer cells with or without CXCR4 expression. Moreover, the effect of AMD070 on the migration and invasion of the cells was similar to that of ADM3100. In a previous clinical trial, AMD070 was able to achieve plasma concentrations of $6.6 \mathrm{mM}$ with an oral administration dose of $400 \mathrm{mg}$ in fasted healthy volunteers (20). It was also demonstrated that leukocytosis followed AMD070 dosing in all subjects, ranging from 1.3 to 2.9 -fold above the baseline, and peaking at 2-4 $\mathrm{h}$ following administration (20). Therefore, as effective CXCR4-related therapies may require daily administration of CXCR4 antagonists to continuously prevent the migration of pre-metastatic cells to metastatic sites, this may lead to chronic leukocytosis. In our prior study, the daily administration of AMD3100 to immunocompetent mice induced transient leukocytosis after 1 day (control, $5,100 / \mu 1$ vs. AMD3100, $8,030 / \mu 1$ ); however, the number of leukocytes in mice treated with AMD3100 gradually decreased, almost to the baseline (unpublished data). Thus, leukocytosis following treatment with AMD070 may be negligible, although we have no data regarding leukocyte changes in mice following treatment with AMD070 in the present study.

In the present study, AMD070 treatment induced no apparent body weight loss during the 49-day observation period. Additionally, we have previously reported that mice inoculated with CXCR4-knockdown cells were significantly heavier than mice inoculated with control cells, and that the production of the cachexia-induced cytokine interleukin (IL)-6 was impaired in these CXCR4-knockdown cells both in vitro and in vivo (7). A number of investigators have reported the importance of IL-6 in cancer cachexia and anorexia in various types of cancer (35). Thus, our data indicated that the blockade of CXCR4 by AMD070 treatment may also inhibit cancer cachexia via the suppression of IL-6 production in CXCR4-related oral cancer.

Several investigators have demonstrated the possible efficacy of AMD070 in the treatment of high-grade malignant tumors $(23,34)$. For example, O'Boyle et al demonstrated that AMD070 abrogated melanoma cell migration towards liver-resident myofibroblasts excreting CXCL12, and that it was significantly more effective than AMD3100 (34). Moreover, Morimoto et al determined that treatment with AMD070 could overcome gemcitabine resistance in pancreatic cancer cells (23). In clinical trials, Stone et al demonstrated that no apparent acute toxicity was present in oral bioavailability studies using AMD070 (20), suggesting that CXCR4 is a safe therapeutic target. In addition, more recent investigations have identified several candidate inhibitors of CXCR4 in CXCL12 competition binding studies (36). Although AMD3100 is the only currently clinically available inhibitor, these new compounds, including AMD070, may have the potential to become novel candidates for CXCR4-targeting therapies.

\section{Acknowledgements}

Not applicable.

\section{Funding}

The present study was supported by a Grant-in-Aid for Scientific Research (C) (nos. 26463046 and 17K11886).

\section{Availability of data and materials}

The datasets used during the present study are available from the corresponding author upon reasonable request.

\section{Authors' contributions}

DU, NK and YM conceived and designed the study. MK, YS, MS, TM, and TH performed the experiments. DU and NK wrote the report. HK reviewed and edited the manuscript. All authors read and approved the manuscript and agree to be accountable for all aspects of the research in ensuring that the accuracy or integrity of any part of the study are appropriately investigated and resolved.

\section{Ethics approval and consent to participate}

All animal experimental protocols were approved by the Animal Research Committee, Tokushima University (Tokushima, Japan).

\section{Consent for publication}

Not applicable.

\section{Competing interests}

The authors state that they have no competing interests.

\section{References}

1. Uchida D, Begum NM, Almofti A, Nakashiro K, Kawamata $H$, Tateishi Y, Hamakawa H, Yoshida H and Sato M: Possible role of stromal-cell-derived factor-1/CXCR4 signaling on lymph node metastasis of oral squamous cell carcinoma. Exp Cell Res 290: 289-302, 2003

2. Uchida D, Begum NM, Tomizuka Y, Bando T, Almofti A, Yoshida $\mathrm{H}$ and Sato M: Acquisition of lymph node, but not distant metastatic potentials, by the overexpression of CXCR4 in human oral squamous cell carcinoma. Lab Invest 84: 1538-1546, 2004. 
3. Almofti A, Uchida D, Begum NM, Tomizuka Y, Iga H, Yoshida $H$ and Sato M: The clinicopathological significance of the expression of CXCR4 protein in oral squamous cell carcinoma. Int J Oncol 25: 65-71, 2004.

4. Onoue T, Uchida D, Begum NM, Tomizuka Y, Yoshida H and Sato M: Epithelial-mesenchymal transition induced by the stromal cell-derived factor-1/CXCR4 system in oral squamous cell carcinoma cells. Int J Oncol 29: 1133-1138, 2006.

5. Uchida D, Onoue T, Tomizuka Y, Begum NM, Miwa Y, Yoshida H and Sato M: Involvement of an autocrine stromal cell derived factor-1/CXCR4 system on the distant metastasis of human oral squamous cell carcinoma. Mol Cancer Res 5: 685-694, 2007.

6. Uchida D, Kuribayashi N, Kinouchi M, Ohe G, Tamatani T, Nagai $\mathrm{H}$ and Miyamoto Y: Expression and function of CXCR4 in human salivary gland cancers. Clin Exp Metastasis 30: 133-142, 2013.

7. Uchida D, Onoue T, Kuribayashi N, Tomizuka Y, Tamatani T, Nagai H and Miyamoto Y: Blockade of CXCR4 in oral squamous cell carcinoma inhibits lymph node metastases. Eur J Cancer 47: 452-459, 2011.

8. De Clercq E: The bicyclam AMD3100 story. Nat Rev Drug Discov 2: 581-587, 2003.

9. Genzyme: Investigator's Brochure for Plerixafor Injection (AMD3100, Mozobil). 1-142, 2012.

10. Müller A, Homey B, Soto H, Ge N, Catron D, Buchanan ME, McClanahan T, Murphy E, Yuan W, Wagner SN, et al: Involvement of chemokine receptors in breast cancer metastasis. Nature 410: 50-56, 2001.

11. Scotton CJ, Wilson JL, Milliken D, Stamp G and Balkwill FR: Epithelial cancer cell migration: A role for chemokine receptors? Cancer Res 61: 4961-4965, 2001.

12. Taichman RS, Cooper C, Keller ET, Pienta KJ, Taichman NS and McCauley LK: Use of the stromal cell-derived factor-1/CXCR4 pathway in prostate cancer metastasis to bone. Cancer Res 62: $1832-1837,2002$.

13. Schrader AJ, Lechner O, Templin M, Dittmar KE, Machtens S, Mengel M, Probst-Kepper M, Franzke A, Wollensak T, Gatzlaff $\mathrm{P}$, et al: CXCR4/CXCL12 expression and signalling in kidney cancer. Br J Cancer 86: 1250-1256, 2002.

14. Zhou Y, Larsen PH, Hao C and Yong VW: CXCR4 is a major chemokine receptor on glioma cells and mediates their survival. J Biol Chem 277: 49481-49487, 2002.

15. Kijima T, Maulik G, Ma PC, Tibaldi EV, Turner RE, Rollins B, Sattler M, Johnson BE and Salgia R: Regulation of cellular proliferation, cytoskeletal function, and signal transduction through CXCR4 and c-Kit in small cell lung cancer cells. Cancer Res 62: 6304-6311, 2002.

16. Cabioglu N, Summy J, Miller C, Parikh NU, Sahin AA, Tuzlali S, Pumiglia K, Gallick GE and Price JE: CXCL-12/stromal cell-derived factor-1alpha transactivates HER2-neu in breast cancer cells by a novel pathway involving Src kinase activation. Cancer Res 65: 6493-6497, 2005.

17. Hartmann TN, Burger JA, Glodek A, Fujii N and Burger M: CXCR4 chemokine receptor and integrin signaling co-operate in mediating adhesion and chemoresistance in small cell lung cancer (SCLC) cells. Oncogene 24: 4462-4471, 2005.

18. Yasumoto K, Koizumi K, Kawashima A, Saitoh Y, Arita Y, Shinohara K, Minami T, Nakayama T, Sakurai H, Takahashi Y, et al: Role of the CXCL12/CXCR4 axis in peritoneal carcinomatosis of gastric cancer. Cancer Res 66: 2181-2187, 2006.

19. Marchesi F, Monti P, Leone BE, Zerbi A, Vecchi A, Piemonti L, Mantovani A and Allavena P: Increased survival, proliferation, and migration in metastatic human pancreatic tumor cells expressing functional CXCR4. Cancer Res 64: 8420-8427, 2004

20. Stone ND, Dunaway SB, Flexner C, Tierney C, Calandra GB Becker S, Cao YJ, Wiggins IP, Conley J, MacFarland RT, et al: Multiple-dose escalation study of the safety, pharmacokinetics, and biologic activity of oral AMD070, a selective CXCR4 receptor inhibitor, in human subjects. Antimicrob Agents Chemother 51: 2351-2358, 2007.
21. Mosi RM, Anastassova V, Cox J, Darkes MC, Idzan SR, Labrecque J, Lau G, Nelson KL, Patel K, Santucci Z, et al: The molecular pharmacology of AMD11070: An orally bioavailable CXCR4 HIV entry inhibitor. Biochem Pharmacol 83: 472-479, 2012.

22. Parameswaran R, Yu M, Lim M, Groffen J and Heisterkamp N: Combination of drug therapy in acute lymphoblastic leukemia with a CXCR4 antagonist. Leukemia 25: 1314-1323, 2011.

23. Morimoto M, Matsuo Y, Koide S, Tsuboi K, Shamoto T, Sato T, Saito K, Takahashi H and Takeyama H: Enhancement of the CXCL12/CXCR4 axis due to acquisition of gemcitabine resistance in pancreatic cancer: Effect of CXCR4 antagonists. BMC Cancer 16: 305, 2016.

24. Bleul CC, Farzan M, Choe H, Parolin C, Clark-Lewis I, Sodroski J and Springer TA: The lymphocyte chemoattractant SDF-1 is a ligand for LESTR/fusin and blocks HIV-1 entry. Nature 382: 829-833, 1996.

25. Nagasawa T, Hirota S, Tachibana K, Takakura N, Nishikawa S, Kitamura Y, Yoshida N, Kikutani H and Kishimoto T: Defects of B-cell lymphopoiesis and bone-marrow myelopoiesis in mice lacking the CXC chemokine PBSF/SDF-1. Nature 382: 635-638, 1996.

26. Oberlin E, Amara A, Bachelerie F, Bessia C, Virelizier JL, Arenzana-Seisdedos F, Schwartz O, Heard JM, Clark-Lewis I, Legler DF, et al: The CXC chemokine SDF-1 is the ligand for LESTR/fusin and prevents infection by T-cell-line-adapted HIV-1. Nature 382: 833-835, 1996.

27. Aiuti A, Webb IJ, Bleul C, Springer T and Gutierrez-Ramos JC: The chemokine SDF-1 is a chemoattractant for human CD34 hematopoietic progenitor cells and provides a new mechanism to explain the mobilization of $\mathrm{CD} 34^{+}$progenitors to peripheral blood. J Exp Med 185: 111-120, 1997.

28. Hwang JH, Hwang JH, Chung HK, Kim DW, Hwang ES, Suh JM, Kim H, You KH, Kwon OY, Ro HK, et al: CXC chemokine receptor 4 expression and function in human anaplastic thyroid cancer cells. J Clin Endocrinol Metab 88: 408-416, 2003.

29. Zhang L, Yeger H, Das B, Irwin MS and Baruchel S: Tissue microenvironment modulates CXCR4 expression and tumor metastasis in neuroblastoma. Neoplasia 9: 36-46, 2007.

30. Scala S, Ottaiano A, Ascierto PA, Cavalli M, Simeone E, Giuliano P, Napolitano M, Franco R, Botti G and Castello G: Expression of CXCR4 predicts poor prognosis in patients with malignant melanoma. Clin Cancer Res 11: 1835-1841, 2005.

31. Scala S: Molecular Pathways: Targeting the CXCR4-CXCL12 axis - untapped potential in the tumor microenvironment. Clin Cancer Res 21: 4278-4285, 2015.

32. Debnath B, Xu S, Grande F, Garofalo A and Neamati N: Small molecule inhibitors of CXCR4. Theranostics 3: 47-75, 2013.

33. Skerlj RT, Bridger GJ, Kaller A, McEachern EJ, Crawford JB, Zhou Y, Atsma B, Langille J, Nan S, Veale D, et al: Discovery of novel small molecule orally bioavailable $\mathrm{C}-\mathrm{X}-\mathrm{C}$ chemokine receptor 4 antagonists that are potent inhibitors of T-tropic (X4) HIV-1 replication. J Med Chem 53: 3376-3388, 2010.

34. O'Boyle G, Swidenbank I, Marshall H, Barker CE, Armstrong J, White SA, Fricker SP, Plummer R, Wright $M$ and Lovat PE: Inhibition of CXCR4-CXCL12 chemotaxis in melanoma by AMD11070. Br J Cancer 108: 1634-1640, 2013.

35. Tisdale MJ: Biology of cachexia. J Natl Cancer Inst 89: 1763-1773, 1997.

36. Van Hout A, D'huys T, Oeyen M, Schols D and Van Loy T: Comparison of cell-based assays for the identification and evaluation of competitive CXCR4 inhibitors. PLoS One 12: e0176057, 2017. 